\title{
TERAPI ENDORPHIN MASSAGE UNTUK MENURUNKAN INTENSITAS NYERI KALA 1 FASE AKTIF PERSALINAN
}

\author{
Rr. Catur Leny W'1, Machfudloh ${ }^{2}$ \\ 1,2 Prodi D3 Kebidanan FK Unissula Semarang \\ Email : caturleny@unissula.ac.id, machfudloh@unissula.ac.id ${ }^{2}$
}

\begin{abstract}
ABSTRAK
Nyeri persalinan dapat menimbulkan stres yang menyebabkan pelepasan hormon yang berlebihan seperti katekolamin dan steroid. Endorphin Massage merupakan sebuah terapi sentuhan/pijatan ringan yang cukup penting diberikan pada wanita hamil, di waktu menjelang hingga saatnya melahirkan. Tujuan penelitian adalah mengetahui pengaruh Endorphin Massage terhadap intensitas nyeri kala I fase aktif pada persalinan. Penelitian ini menggunakan jenis penelitian kuantitatif quasi eksperimental design, dengan rancangan yang digunakan adalah posttest only control group design dengan sampel 30 responden diambil dengan menggunakan teknik Acidental sampling di BPM Wilayah Puskesmas Demak. Data yang digunakan data primer dengan instrument berupa lembar checklist. Analisa data menggunakan uji Spearman Rank. Hasil Penelitian ada pengaruh pemberian Terapi Endorphin Massage terhadap intensitas nyeri kala I fase aktif persalinan yaitu didapatkan hasil $p<0,05$ yaitu $p=0,004$. Simpulan intesitas nyeri responden sebelum dilakukan Endorphin Massage sebagian besar responden mengalami nyeri berat dengan skala 8-9, Intesitas nyeri responden setelah dilakukan Endorphin Massage sebagian besar responden mengalami nyeri sedang dengan skala 6-7. Ada pengaruh Endorphin Massage terhadap intensitas nyeri kala I fase aktif pada persalinan.
\end{abstract}

Kata kunci : Endorphin massage; Intensitas nyeri; Persalinan

\section{ENDORPHIN MASSAGE THERAPY TO REDUCE THE INTENSITY OF PAIN DURING THE ACTIVE PHASE OF LABOR}

\begin{abstract}
Birth pain may cause stress that lead tobring out excessive hormones such as catecholamines and steroids. Endorphin massage is a touch therapy orgentlemassage which is important enough for pregnant women before giving birth. The aim of this research is to know the effect of Endorphin Massageonpain intensity during active phase of first stage in labor. This research uses quantitative quasi experimental design, with the design used is posttest for control group design. Independent variable is endorphin massage.Variable dependent is pain intensity of acitivephase of first stage in labor, with 30 respondents of sample wich is taken by using technique of Acidental sampling. This research took a place in BPM area of public health center Demak. The data was gathered through observation using checklist form. The data was analyzed using Spearman Rank test. The result of the research is there is an effect of Endorphin Massage onpain intensity of acitivephase of first stage in labor with $p<0,05, p=0,004$. The conclusion is most of respondents had severe pain with scale 8-9before Endorphin Massage, and most of the respondentshad moderate pain with scale 6-7after Endorphin Massage. There is an effect of Endorphin Massage on pain intensity of acitivephase of first stage in labor.
\end{abstract}

Keywords: Endorphin massage; Labor; Pain Intensity

Jurnal SMART Kebidanan Sekolah Tinggi Ilmu Kesehatan (STIKes) Karya Husada Semarang www.stikesyahoedsmg.ac.id/ojs/index.php/sjkb 


\section{Pendahuluan}

Nyeri persalinan dapat menimbulkan stres yang menyebabkan pelepasan hormon yang berlebihan seperti katekolamin dan steroid. Hormon ini dapat menyebabkan terjadinya ketegangan otot polos dan vasokonstriksi pembuluh darah. Hal ini dapat mengakibatkan penurunan kontraksi uterus, penurunan sirkulasi uteroplasenta, pengurangan aliran darah dan oksigen ke uterus, serta timbulnya iskemia uterus yang membuat impuls nyeri bertambah banyak (Sumarah, 2009). Faktor-faktor yang mempengaruhi nyeri persalinan yang disebutkan oleh Bobak (2005) diantaranya pengalaman masa lalu, paritas, budaya, keletihan dan emosi.

Salah satu cara penatalaksanaan nonfarmakologis untuk mengurangi nyeri persalinan dengan endorphine massage. Endorphin Massage merupakan sebuah terapi sentuhan/pijatan ringan yang cukup penting diberikan pada wanita hamil, di waktu menjelang hingga saatnya melahirkan. Hal ini disebabkan karena pijatan merangsang tubuh untuk melepaskan senyawa endorphin yang merupakan pereda rasa sakit dan dapat menciptakan perasaan nyaman, Selama ini endorphin sudah dikenal sebagai zat yang banyak manfaatnya (Kuswandi, 2011).

Seorang ahli kebidanan, Constance Palinsky, tergerak menggunakan endorphin untuk mengurangi atau meringankan rasa sakit pada ibu yang akan melahirkan. Diciptakanlah Endorphin Massage, yang merupakan teknik sentuhan serta pemijatan ringan, yang dapat menormalkan denyut jantung dan tekanan darah, serta meningkatkan kondisi rileks dalam tubuh ibu hamil dengan memicu perasaan nyaman melalui permukaan kulit. Terbukti dari hasil penelitian, teknik ini dapat meningkatkan pelepasan zat oksitosin, sebuah hormon yang memfasilitasi persalinan (Mongan, 2009).

Penelitian ini diperkuat oleh penelitian yang dilakukan sebelumnya, antara lain hasil penelitian yang dilakukan I Wayan Agung Indrawan (2012) menyatakan bahwa semakin tinggi tingkat stresnya maka semakin lama persalinannya. Sebaliknya, semakin rendah tingkat stresnya maka semakin cepat persalinannya. Penelitian Nurrochmi dkk (2013) menunjukkan bahwa terdapat pengaruh antara pemberian kombinasi metode Zilgrei dan endorphin massage pada ibu inpartu primigravida terhadap lamanya kala I fase aktif. Dengan kata lain, hipotesis kerja peneliti terbukti yang berarti pemberian intervensi kombinasi metode Zilgrei dan endorphin massage efektif dalam mempercepat kala I fase aktif persalinan. Penelitian Azizah dkk (2011) Ada pengaruh endorphin massage terhadap intensitas nyeri kala I persalinan normal di Puskesmas Wilayah Kabupaten Demak. 
Hasil survey pendahuluan, ibu sering kali merasa cemas dan khawatir pada proses persalinan sehingga menyebabkan nyeri persalinan yang semakin bertambah terutama pada kala I. Bahkan pada ibu primipara menyatakan tidak tahan dengan nyeri yang dirasakan pada saat ibu merasakan nyeri yang sangat dan kecemasan yang memuncak dapat berakibat trauma bagi ibu maupun janin. Di Puskesmas Wilayah Kabupaten Demak belum memberikan terapi Endorphin Massage kepada ibu hamil pada kelas ibu hamil.

\section{Tinjauan Teoritis}

1. Persalinan

Persalinan adalah rangkaian proses berakhir dengan pengeluaran hasil konsepsi oleh ibu. Proses ini dimulai dengan kontraksi persalinan sejati, yang ditandai oleh perubahan progresif pada serviks, dan diakhiri dengan pelahiran plasenta (Varney, 2007). Tahapan persalinan ada 4 kala yaitu dalam persalinan terdapat 4 kala yaitu: 1) kala I (Pembukaan); 2) kala II (Pengeluaran Janin); 3) kala III (Pelepasan Plasenta) dan kala IV (Observasi).

2. Nyeri Persalinan

Kontraksi miometrium pada persalinan dapat menyebabkan nyeri, sehingga istilah nyeri persalinan digunakan untuk mendeskripsikan proses ini (Cunningham et al, 2005). Banyak faktor yang mempengaruhi nyeri persalinan, baik faktor internal maupun eksternal yang meliputi paritas, usia, budaya, mekanisme koping, emosional, tingkat pendidikan, lingkungan, kelelahan, kecemasan, lama persalinan, pengalaman masa lalu, support system dan tindakan medik (Handerson, 2006).

3. Terapi Endorphin

Menurut Kuswandi (2011) Endorphin Massage merupakan sebuah terapi sentuhan/pijatan ringan yang cukup penting diberikan pada wanita hamil, diwaktu menjelang hingga saatnya melahirkan. Hal ini disebabkan karena pijatan merangsang tubuh untuk melepaskan senyawa endorphin yang merupakan pereda rasa sakit dan dapat menciptakan perasaan nyaman (Azizah, dkk, 2011).

Riset membuktikan bahwa teknik ini meningkatkan pelepasan hormon endorphin dan oksitosin, sebuah hormon yang memfasilitasi persalinan (Aprilia, 2010). Macammacam gerakan massage yaitu (1) Mengusap (Efflurage/strocking) (2) Meremas (Petrisage), (3) Friction , (4) Menggetar (vibration), (5) Memukul (tapotement) 
tapotage). Variasi gerakan tapotement, yaitu : Memukul (beating), Mencincang (hacking) dan Menepuk (clapping).

\section{Metode Penelitian}

Penelitian ini menggunakan jenis penelitian kuantitatif quasi experimental design, dengan rancangan yang digunakan adalah posttest only control group design. Populasi dan sampel penelitian ini adalah semua ibu bersalin di Puskesmas Wilayah Kabupaten Demak pada bulan Juni sampai dengan Agustus 2017 sebanyak 20 orang dengan teknik purpossive sampling. Tehnik pengambilan data menggunakan instrument checklist. Kriteria inklusi pada penelitian ini adalah ibu hamil normal dengan umur kehamilan lebih dari 36 minggu berada di Puskesmas Wilayah Kabupaten Demak Tahun 2017.

\section{Hasil Penelitian}

Hasil penelitian pengaruh terapi endorphin massage Pada ibu inpartu terhadap intensitas nyeri kala 1 fase aktif
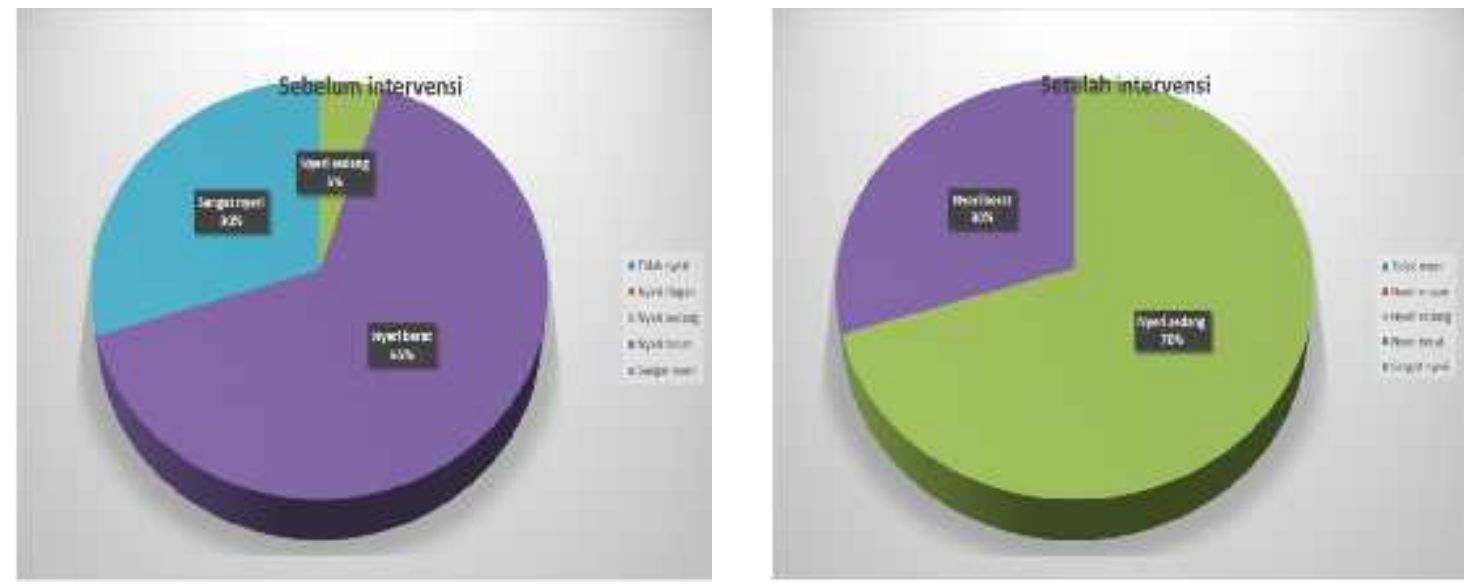

Diagram 1

Hasil Intensitas Skala Nyeri Responden Sebelum dan setelah Terapi Endorphin Massage di Puskesmas Wilayah Demak

Berdasarkan diagram 1 bahwa dari 20 responden, sebagian besar responden mengalami nyeri berat sebelum dilakukan Endorphin Massage sebanyak 6 orang (30\%) sangat nyeri, 13 orang $(65 \%)$ nyeri berat dan 1 orang (5\%) nyeri sedang. Setelah dilakukan 
Endorphin Massage terjadi penurunan intensitas nyeri berat sebanyak 6 orang ( $30 \%$ ) dan nyeri sedang sebanyak 14 orang $(70 \%)$.

Tabel 1 Hasil Intensitas Skala Nyeri Responden Sebelum dan Setelah Terapi Endorphin Massage di Puskesmas Wilayah Demak

\begin{tabular}{|c|c|c|c|}
\hline Responden & Sebelum intervensi & Responden & Setelah intervensi \\
\hline 1 & Nyeri berat & 1 & Nyeri sedang \\
\hline 2 & Nyeri berat & 2 & Nyeri berat \\
\hline 3 & Nyeri berat & 3 & Nyeri berat \\
\hline 4 & Sangat nyeri & 4 & Nyeri sedang \\
\hline 5 & Nyeri berat & 5 & Nyeri sedang \\
\hline 6 & Sangat nyeri & 6 & Nyeri berat \\
\hline 7 & Sangat nyeri & 7 & Nyeri berat \\
\hline 8 & Nyeri berat & 8 & Nyeri sedang \\
\hline 9 & Sangat nyeri & 9 & Nyeri sedang \\
\hline 10 & Nyeri berat & 10 & Nyeri sedang \\
\hline 11 & Nyeri berat & 11 & Nyeri sedang \\
\hline 12 & Nyeri berat & 12 & Nyeri sedang \\
\hline 13 & Nyeri berat & 13 & Nyeri berat \\
\hline 14 & Nyeri berat & 14 & Nyeri sedang \\
\hline 15 & Nyeri berat & 15 & Nyeri sedang \\
\hline 16 & Sangat nyeri & 16 & Nyeri sedang \\
\hline 17 & Nyeri berat & 17 & Nyeri sedang \\
\hline 18 & Nyeri berat & 18 & Nyeri sedang \\
\hline 19 & Sangat nyeri & 19 & Nyeri berat \\
\hline 20 & Nyeri sedang & 20 & Nyeri sedang \\
\hline
\end{tabular}

Berdasarkan tabel 1 menunjukkan bahwa dari 20 responden sebagian besar responden mengalami sangat nyeri dan nyeri berat sebelum dilakukan Terapi Endorphin Massage sebanyak 19 orang (95\%), setelah dilakukan Terapi Endorphin Massage menurun menjadi nyeri sedang sebanyak 14 orang $(70 \%)$ dan 3 orang (15\%) mengalami penurunan dari skala sangat nyeri ke nyeri berat, serta terdapat 3 orang (15\%) yang tidak mengalami perubahan (nyeri berat). 
Tabel 2 Pengaruh Pemberian Endorphin Massage Terhadap Intensitas Nyeri Kala I Fase Aktif Persalinan di Puskesmas Wilayah Demak

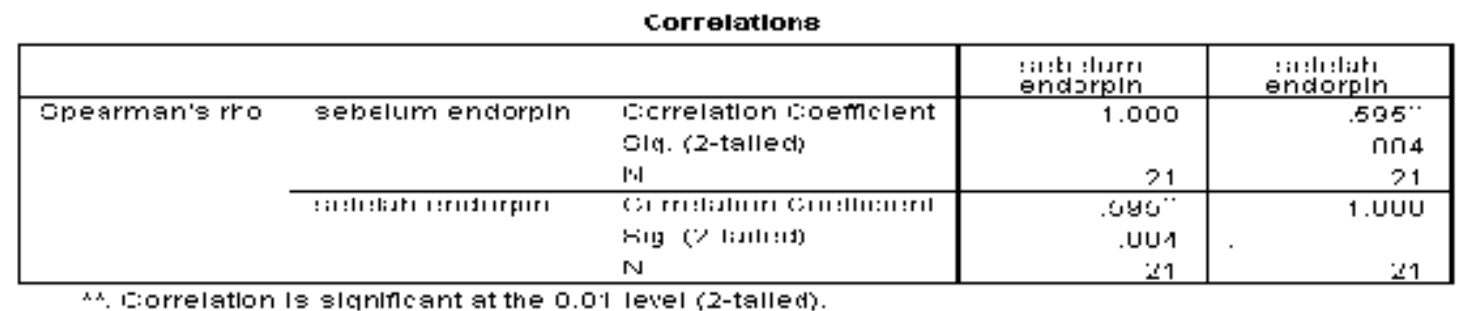

Dari tabel 2 didapatkan hasil ada pengaruh pemberian Endorphin Massage terhadap intensitas nyeri kala I fase aktif persalinan dengan $\mathrm{p}=0,004$.

\section{Pembahasan}

Hasil penelitian dapat disimpulkan bahwa responden yang diberikan Terapi Endorphin Massage sebagian besar mengalami penurunan skala nyeri. Terapi Endorphin Massage membuat responden merasa nyaman, relaks dan ada responden yang tertidur saat dilakukan Terapi Endorphin Massage oleh suami, keluarga ataupun bidan jaga. Responden juga merasakan perubahan setelah dilakukan massage berupa rasa lebih rileks, lebih nyaman walaupun tidak menurunkan nyeri secara signifikan. Responden yang tidak mengalami perubahan setelah dilakukan Endorphin Massage sebanyak 3 orang, setelah diamati terdapat beberapa faktor yang menyebabkan tidak adanya perubahan yaitu kehamilan/gravida yang pertama sehingga belum mempunyai pengalaman masa lalu, dan responden yang memiliki ambang nyeri berbeda sehingga tingkat nyeri setiap orang berbeda.

Metode pengontrolan nyeri secara nonfarmakologi sangat penting karena tidak membahayakan bagi ibu maupun janin, tidak memperlambat persalinan jika diberikan kontrol nyeri yang kuat, dan tidak mempunyai efek alergi maupun efek obat. Berdasarkan fakta, teori dan kajian diatas menunjukkan bahwa Endorphin massage dapat memberikan efek yang signifikan menurunkan nyeri pada ibu bersalin kala I.

\section{Kesimpulan}

Terapi endorphin massage mampu menurunkan intensitas nyeri kala 1 fase aktif persalinan 


\section{Saran}

Bidan dapat mempromosikan dan mengaplikasikan teknik endorphin massage untuk mengurangi intensitas rasa nyeri pada persalinan kala I, terutama bagi ibu hamil trimester III pada kelas ibu hamil, dan menjelang persalinan pada kala I serta melibatkan suami dan keluarga untuk melakukan teknik endorphin massage.

Peneliti selanjutnya untuk melakukan penelitian tentang Teknik Endorphin Massage untuk mengurangi intensitas nyeri kala I pada ibu bersalin dengan mengikutsertakan variabel lain dalam unit analisis statistik

\section{Daftar Pustaka}

Azizah, Iin Nur, dkk. 2011. Pengaruh Endorphin Massage Terhadap Massage Terhadap Instensitas Nyeri Kala I Persalinan Normal Ibu Primipara di BPS S dan M Demak.

Bobak, Lowdermilk and Jensen. 2005. Buku Ajar Keperawatan Maternitas, Eds 4. Jakarta: Penerbit EGC.

Danuatmaja, Bonny. 2008. Persalinan Normal Tanpa Rasa Sakit. Puspa Swara. Jakarta.

Dinas Kesehatan Propinsi Jawa Tengah. 2012. Profil kesehatan Jawa Tengah Tahun 2012.

Gadysa, G. (2009). Persepsi Ibu Tentang Metode Masase. Diambil 27 September 2010, dari http://luluvikar.wordpress

Indrawan, Agung I Wayan. 2012. Hubungan Antara Stres Dengan Lama Fase Aktif Kala I Persalinan Pada Ibu Primigravida di RSUD Dr. Saiful Anwar Malang.

Kementrian Kesehatan Republik Indonesia. 2014. Profil Kesehatan Indonesia Tahun 2014.

Kuswandi, 2011. Asuhan Kebidanan: Persalinan dan Kelahiran. Buku Kedokteran EGC, Jakarta.

Manuaba IBG, 2012. Kapita Selekta Penatalaksanaan Rutin Obstetri Ginekologi dan KB.

Martin, 2011. Asuhan Keperawatan Maternitas. Jakarta : Salemba Medika

Mongan, M. 2009. Hypno Birthing : Metode Melahirkan Secara Aman, Mudah dan Nyaman. Jakarta : PT Bhuana Ilmu Populer.

Nurrochmi dkk. (2013) Pengaruh Kombinasi Metode Zilgrei Dan Endorphin Massage Pada Ibu Inpartu Primigravida Terhadap Lamanya Kala I Fase Aktif Di Rsud Indramayu Periode April-Mei 2013.

Risanto, W. 2010. Pengaruh Dukungan Psikososial selama Persalinan Terhadap RasaNyeri saat Persalinan, Lama Persalinan dan Kecemasan. Yogyakarta. UGM. 
Sulistyawati dan Nugraheny. 2010. Asuhan Kebidanan Ibu Bersalin. Jakarta. Salemba Medika.

Sumarah, 2009. Perawatan Ibu Bersalin: Asuhan Kebidanan Pada Ibu Bersalin. Fitramaya, Yogyakarta.

Varney, Hellen. 2007. Buku Ajar Asuhan Kebidanan. Jakarta. EGC.

Wiknjosastro, Hanifa 2010. Ilmu Kebidanan. Yayasan Bina Pustaka Sarwono Prawirohardjo, Jakarta. 